\title{
Bacterial etiologic agents causing neonatal sepsis and associated risk factors in Gondar, Northwest Ethiopia
}

\author{
Tsehaynesh G/eyesus ${ }^{1}$, Feleke Moges ${ }^{2}$, Setegn Eshetie ${ }^{2 *}$, Biruk Yeshitela ${ }^{3}$ and Ebba Abate $^{2}$
}

\begin{abstract}
Background: Neonatal sepsis is a blood stream infection which is seen in the first month of life of the neonate. Bacterial profile of neonatal septicemia is constantly changing thus, current knowledge on the patterns of bacterial isolates, its antibiotic resistance profile, and associated factors, are essential to design and implement appropriate interventions. Therefore, the aim of this study was to identify bacterial etiologic agents, their antimicrobial susceptibility pattern and associated risk factors of neonatal sepsis among neonates.
\end{abstract}

Methods: A cross- sectional study was conducted among neonates suspected to sepsis attending University of Gondar Hospital from September/2015 to May/2016. A total of 251 consecutive neonates with clinical sign and symptoms of sepsis were included in the study. Blood sample was collected and directly inoculated into Trypton soya broth bottle and incubated at $37^{\circ} \mathrm{C}$. After $24 \mathrm{~h}$ of incubation it was sub- cultured in to blood agar plate, chocolate agar plate, manitol salt agar and Macconkey. The bacterial pathogens and antimicrobial susceptibility tests were identified using standard microbiological methods. Bivariate and multivariate logistic regressions were used to identify possible associated risk factors. Prior to the study ethical clearance was obtained from the School of Biomedical and Laboratory Sciences, University of Gondar.

Results: Of the 251 study participants suspected of neonatal sepsis, 117 (46.6\%) showed bacterial growths, of them 120 bacteria were isolated. Gram positive bacteria were commonly isolated 81 (67.5\%).The commonly isolated bacterial species were S. aureus 49 (40.8\%) followed by coagulase negative Staphylococci 26 (21.6\%) and K. pneumoniae19 (15.8\%). The overall rate of multidrug resistance isolates was 78 (65\%: Cl 95\%: 56.7-72. 5\%). Multidrug resistant (MDR) among Gram positive and negative bacteria were 56 (69.1\%) and 22 (56.4\%), respectively. Independent risk factors for the occurrence of neonatal sepsis were; Apgar score $<7 / 5 \mathrm{~min}$ (Adjusted odds ratio $[A O R]=0.5)$, birth weight $<1.5 \mathrm{~kg}(\mathrm{AOR}=12.37)$, birth weight, 1.5-2.5 $\mathrm{kg}(\mathrm{AOR}=2.6)$, gestational week $<37$ weeks $(A O R=9)$ and caesarian section delivery $(A O R=5.2)$.

Conclusion: The isolation rate of bacterial pathogens in neonatal sepsis was considerably high. In addition, nearly $70 \%$ of isolates were MDR strains. Low birth weight, low Apgar score, preterm delivery and caesarian section modes of delivery were associated risk factors. Therefore, appropriate antenatal care follow up, and health education should be encouraged, especially on the importance of natural way of delivery.

Keywords: Neonate, Sepsis, Antimicrobial susceptibility, Gondar, Ethiopia

\footnotetext{
* Correspondence: wolet03.2004@gmail.com

${ }^{2}$ Department of Medical Microbiology, School of Biomedical and Laboratory

Sciences, College of Medicine and Health Sciences, University of Gondar,

Gondar, P. O. Box: 196, Ethiopia

Full list of author information is available at the end of the article
} 


\section{Background}

Neonatal sepsis is a systemic infections of the newborn such as septicemia, meningitis, pneumonia, arthritis, osteomyelitis, and urinary tract infections [1]. The clinical syndrome of the disease can be influenced by the virulence of the pathogen, the portal of entry, the susceptibility and response of the host, and the temporal evolution of the condition [2]. Fever, temperature instability, vomiting, diarrhea, irritability, lethargy, breathing problem, low blood sugar, jaundice, reduced sucking and seizures are the most common symptoms of neonatal sepsis [3]. Neonatal sepsis may be classified according to the time of onset of the disease: early onset and late onset. Early-onset of neonatal sepsis refers to the presence of a confirmed infection in the blood or cerebrospinal fluid (CSF) of patients younger than 3 days of life, and late-onset of neonatal sepsis refers to the onset of such infection between 3 and 28 days [4, 5].

The distinction has clinical relevance, as early onset of neonatal sepsis disease is mainly occurred before and during delivery, whereas late onset of neonatal sepsis is possible due to bacteria acquired after delivery through hospital or community acquired source of infections [6, 7]. Organisms causing early onset of neonatal sepsis are typically colonizers of the maternal genitourinary tract, leading to contamination of the amniotic fluid, placenta, cervix, or vaginal canal. The pathogen may ascend when the amniotic membranes rupture or prior to the onset of labor, causing an intra-amniotic infection [8].

Bacteria, such as Streptococcus, L. monocytogenes, E. faecalis,E. faecium, group D Streptococci, $\alpha$-hemolytic Streptococci and Staphylococci,S. pneumoniae,H. influenzae type $\mathrm{B}$, are recognized as the principal cause of early neonatal sepsis. Less commonly, $N$. meningitidis and $N$. gonorrhoeae have been also reported as a cause of neonatal septicemia and Gram-negative enteric organisms predominantly E. coli, Klebsiella species are included $[9,10]$. On the other hand, late-onset sepsis is predominantly caused by Staphylococci species and E. coli and most frequently related with low birth weight of infants and use of intravascular catheters, endo-tracheal intubation, assisted ventilation, surgery, contact with hand of colonized personnel and contact with contaminated equipment as the main risk factors for late onset of neonatal sepsis. Sometimes E. cloacae or Citrobactor from blood or CSF may be due to contaminated feedings. Contaminated respiratory equipment is suspected in outbreaks of hospital-acquired $P$. aeroginosa pneumonia or sepsis $[11,12]$.

Neonatal sepsis remains public health threat and contributing a significant challenge to the management of care groups for neonates and infants. It has been explained that neonates are at the highest risk for bacterial sepsis, with the prevalence at 1 to 10 per 1000 live births worldwide [13]. Globally each year over 4 million neonates died within 28 days of birth [14]. Neonatal mortality is still the highest mortality in human life. It has a close relation to infant mortality rate, which is used as the indicator to assess health development in countries [15]. Besides, a recent global report has also claimed that the infant mortality rate was 29 per 1000 live births [16]. The most common causes of death in the neonatal period are infections, including septicemia, meningitis, respiratory infections, diarrhea, and neonatal tetanus (32\%), followed by birth asphyxia and injuries (29\%), and prematurity (24\%) [17].

Aside from the burden, continuous evolution of drug resistance of pathogens causing neonatal sepsis becomes a potential disastrous problem. The situation is worse in developing countries because of lack of legislation, overthe-counter sale of antibiotics and poor sanitary conditions. Notably, methicillin resistance S.aureus (MRSA), extended spectrum beta lactamase (ESBL) producing bacteria and MDR Gram negative organisms represent the principal setbacks to fight against infections. Most Gram negative bacteria are now resistant to ampicillin and cloxacillin and many are becoming resistant to gentamicin $[18,19]$.

The pattern of bacterial organisms causing neonatal sepsis constantly changes and the emergence of resistant bacteria has complicated the problem further. Therefore, this study aimed to assess bacterial etiologic agents, their antimicrobial susceptibility pattern and possible associated risk factors among neonatal patients with sepsis.

\section{Methods}

Study area, study design and study population

A prospective cross-sectional study was conducted among all admitted neonates for sepsis at the University of Gondar Hospital from September/2015 to May/2016. Diagnosis of neonatal sepsis remains challenging in this hospital, and mainly depends on clinical decision.

\section{Inclusion criteria}

Neonates with clinical sign and symptoms of sepsis at the time of admission or who develop sepsis during their stay in hospital were included in this study.

\section{Exclusion criteria}

Neonates with sepsis, who started antibiotic therapy, were excluded from the study.

\section{Study variables}

Presence of bacterial infection was dependent variable, whereas independent variable were age, sex, occupation, weight at birth, gestational week, mode of delivery, 
maternal health condition (fever, urinary tract infection), bottle feeding, Apgar score at $5 \mathrm{~min}$, and skin or local infection.

\section{Definition of terms}

Bacteremia means the presence of bacteria in the blood stream, which may or may not be caused by infectious agents. Septicemia, on the other hand, it is serious disease characterized by systemic signs, and the presence of bacteria and their toxins in the blood stream.

\section{Data collection and laboratory methods Socio demographic data}

Socio- demographic data of the study participants and associated risk factors for neonatal sepsis were collected using structured questionnaire. Questionnaire was checked for its completeness and validity prior to the collection of data. The pre test of the questionnaire was conducted among neonates with suspicion of sepsis in Bahirdar hospital (Additional file 1: Questionnaire).

\section{Sample collection and processing}

After getting written consent from guardian two bottle of blood samples ( $1 \mathrm{ml}$ for each bottle) from two different sites of peripheral vein were collected aseptically (disinfecting with 70\% alcohol and 2\% tincture of iodine) by experienced nurses prior to any antibiotic use. The collected blood sample was inoculated directly into Trypton soya broth blood culture medium bottles (Oxoid LTD) and sent to the medical microbiology laboratory for culture and drug susceptibility testing. The blood cultures were incubated aerobically at $37{ }^{\circ} \mathrm{C}$ and observed daily for the first 3 days for the presence of visible microbial growth by one of the following: haemolysis, air bubbles (gas production), and coagulation of broth. At the same time, subcultures were made during successive days on enriched and selective media including blood agar plate (Oxoid LTD), chocolate agar plat (incubated at $5 \% \mathrm{CO}_{2}$ atmosphere), MacConkey (Oxoid Ltd. Basingstoke, Hampshire, UK), and manitol salt agar plates and examined for growth after 24-48 h of incubation.

The same protocol was repeated until the 7 th day before blood cultures were considered to be free of microorganisms. Isolates obtained were identified by standard microbiological techniques namely, Gram staining, colony characteristics, and biochemical properties including catalase, coagulase (free and bound), growth on manitol salt agar, and hemolytic activity on blood agar plate for Gram positive isolates, and triple sugar iron, motility, indole, citrate utilization, urease, oxidase and $\mathrm{H} 2 \mathrm{~S}$ production for Gram negative isolates [20]. As described above two aerobic blood culture bottles were used for each patient, and growth in both bottles was considered as positive. Thus, growth of bacteria only from one bottle did not regard as pathogen and considered as contamination.

\section{The antimicrobial susceptibility tests}

Antimicrobial susceptibility test was carried out for each identified bacteria based on Clinical and Laboratory Standard Institute guideline by using disc diffusion method on Muller Hinton agar for non-fastidious organisms and Muller Hinton agar with 5\% defibrinated sterile sheep blood for fastidious organisms [21].

Three to five pure colony of the test organism was taken by using a sterile wire loop and emulsify in $2 \mathrm{ml}$ of nutrient broth. The bacterial suspensions turbidity was matched and checked with 0.5 McFarland standards. Then a sterile cotton swab was dipped in to the suspension and squeeze free from excess fluid against the side of test tube. The test organisms were uniformly seed on the surface of Muller-Hinton agar for non fastidious group and Muller Hinton agar with 5\% defibrinated sterile sheep blood for fastidious group and expose to a concentration gradient of antibiotic diffusing from antibiotic impregnated paper disc into the agar medium and the medium was incubated at $35^{\circ} \mathrm{C}$ for $18-24 \mathrm{~h}$ [22].

The following antimicrobial disks were used (Oxoid UK), Amoxicillin-clavulanate (AMC:20/10 $\mu \mathrm{g}$ ), penicillin (P:10 unit), trimethoprim-sulfamethoxazole (SXT:1.25/ $23.75 \mu \mathrm{g})$, erythromycin (E:15 $\mu \mathrm{g})$, tetracycline (TE: $30 \mu \mathrm{g})$, clindamycin (DA:2 $\mu \mathrm{g})$, chloramphenicol (CAF:30 $\mu \mathrm{g}$ ), ampicillin (AMP:10 $\mu \mathrm{g}$ ), gentamicin $(\mathrm{CN}: 10 \mu \mathrm{g})$, amikacin (AK:30 $\mu \mathrm{g})$, ciprofloxacin (CIP: $5 \mu \mathrm{g})$, ceftazidime (CAZ: $30 \mu \mathrm{g})$,ceftriaxone (CRO:30 $\mu \mathrm{g}$ ) and cefoxitin (CXT:30 $\mu \mathrm{g})$. Grades of susceptibility pattern were interpreted by comparison of the zone of inhibition according to Clinical and Laboratory Standard Institute 2014 guideline [21].

\section{Quality control}

All materials, equipment and procedures were adequately controlled. Pre-analytical, analytical and postanalytical stages of quality assurance that are incorporated in standard operating procedures of the medical microbiology laboratory were strictly followed. The sterility of culture media was ensured by incubating $5 \%$ of each batch of the prepared media at $37^{\circ} \mathrm{C}$ for $24 \mathrm{~h}$. Performance of all prepared media was also checked by inoculating international standard-strains such as E.coli (ATCC 25922) Gram negative bacteria, S. aureus (ATCC 25923) for Gram positive bacteria and N. gonorrhoeae (ATCC49226) for fastidious bacteria. To standardize the inoculums density of bacterial suspension for the susceptibility test, 0.5 McFarland standards was used [20]. To ensure the accuracy of data, double data entry method was used. 


\section{Data analysis and interpretation}

Data were collected and analyzed for the presence and frequency of different bacterial isolates, antibiotic susceptibility pattern and associated risk factors. The findings were entered and analyzed using SPSS version 20. Frequencies and cross tabulations were used to summarize descriptive statistics. Univariate and multivariate logistic regression analyses were used to assess the possible risk factors of neonatal sepsis infection. Descriptive statistics was also used to explain antimicrobial susceptibility patterns. Odds ratio and 95\% confidence interval was computed to assess the presence and degree of association between dependent and independent variables. $P$-value $<0.05$ was considered statistically significant for all cases.

\section{Results}

\section{Characteristics of study participants}

Of the total study participants $(n=251), 149(59.4 \%)$ were male, 184 ( $73.3 \%)$ of the neonates were age $\leq 3$ days (early onset) and146 (58.2\%) were from urban residence. Of the total neonates $46(18.3 \%)$ had very low birth weight $(<1.5 \mathrm{~kg}), 92(36.6 \%)$ were preterm $(<37$ week gestation), 160 (63.7\%) were delivered by spontaneous vaginal delivery. It was observed that $55(21.9 \%)$ of the neonates mothers had history of urinary tract infection (UTI) during gestational period (Table 1).

\section{Magnitude and bacterial profiles among neonatal septicemia}

Of the study participants with neonatal septicemia, $117(46.62 \%)$ showed bacterial growth and of these 120 different kinds of bacterial pathogens were identified. Three of blood cultures (2.5\%) showed mixed growth (poly microbial), while the 114 (97.5\%) showed non duplicate growth. The rest 134 (53.4\%) had no bacterial growth. Gram positive bacterial species were commonly isolated $81(67.5 \%)$ than the Gram negative bacterial species 39 (32.5\%). The commonly isolated bacteria were S. aureus 49 (40.9\%) followed by CoNS 26 (21.7\%) and K. pneumoniae 19 (15.8\%) (Table 2).

The predominant organisms during the first 3 days of life were Gram positive, accounting for 57 (65.5\%) of the 87 (72.5\%) isolates. Between 3 and 28 days of life, Gram negative and Gram positive isolates accounted for 9 (27.28\%) and $24(72.72 \%)$ of the 33 isolated organisms, respectively. The single predominant Gram positive organism in both age groups was S. aureus 49 (40.83\%). Among Gram negatives, K. pneumonia 19 (15.83\%) was the predominant causative agent in both age groups (Table 2).
Antimicrobial susceptibility pattern of bacterial isolates from neonatal septicemia

From the total isolates only 11 (9.2\%, 95\% CI, 4.4-15\%) isolates were susceptible to all tested antibiotics. Over all in Gram positive isolates high resistance rate were observed to penicillin 42 (51.8\%), ampicillin 30 (37\%) and trimethoprim- sulfamethoxazole 34 (42\%). On the other hand, Gram positive bacteria showed least resistance rate to clindamycin $7(8.6 \%)$ andciprofloxacin 16 (19.7\%). As indicated Table 3, species specific antibiotic resistance rates showed that more than $35 \%$ of $S$. aureus isolates were resistant to penicillin, ampicillin, Trimethoprim- sulfamethoxazole, gentamicin anderythromycin.

Susceptibility pattern in Gram negative isolates indicates that high susceptibility rate seen in amikacin 37 (94.9\%), ciprofloxacin, ceftazidamide and gentamicin each $34(87.2 \%)$ and highly resistance seen in ampicillin 33 (84.6\%), ceftriaxone 22 (56.4\%) and trimethoprim/ sulfamethoxazole 17 (43.58\%). Species specific antibiotic resistance in Gram negative has also indicated, E.coli were resistant to ampicillin $8(66.7 \%)$ but relatively no resistance rates were noted to ciprofloxacin and amikacin. K. pneumonia was highly resistance to ampicillin 18 (94.75\%), ceftriaxone 15 (78.9\%) and trimethoprim/sulfamethoxazole 8 (42.1\%). It was highly sensitive to ciprofloxacin and gentamicin 16 (84.2\%) each (Table 4).

\section{Multi drug resistance pattern of bacterial isolates from neonatal septicemia}

Among the total isolates, 78 (65\%, 95\% CI: 56.7-72.5\%) were resistance to three or more different class of antibiotics. Among MDR strains, 21 (17.5\%) isolate were resistant to three classes of antibiotics, the rest 57 (47.5\%) were resistant to greater than three classes of antibiotics. Result of drug resistance patterns compared within species specific showed that, $33(67.3 \%)$ of S. aureus, 8 $(66.7 \%)$ of $E$. coli and 16 (84.2\%) of $K$. pnuemonae were MDR isolates. Among the total isolates of $S$. aureus, 13 (26.5\%) of them were found to be MRSA (Table 5).

\section{Associated risk factors related to neonatal septicemia}

Risk factors associated with neonatal septicemia were analyzed. Univariate and multivariate analysis showed that very low birth weight with adjusted odds ratio (AOR) 12.37 (95\% CI: 4.135-37.04), low birth weight with AOR 2.63 (95\% CI: 1.149-6.09),caesarean section mode of delivery with AOR 5.2(95\% CI: 2.36-11.37), Apgar score < 7 with AOR 0.438 (95\% CI: 0.215-0.892) and preterm gestational week with AOR 8.99 (95\% CI: 4.175-19.38) were associated with neonatal septicemia (Table 6).

Multivariate analysis result indicates that gestational week has significant association which means that neonates born in gestation $<37$ weeks had almost nine 
Table 1 Distributions of bacterial isolates per characteristics of study participants with neonatal septicemia attending the University of Gondar Hospital, North west Ethiopia, September/2015 to May/2016, ( $N=251)$

\begin{tabular}{|c|c|c|c|c|}
\hline \multirow[t]{2}{*}{ Characteristic } & & \multicolumn{3}{|c|}{ Organism isolated } \\
\hline & & Yes n (\%) & No n (\%) & Total n (\%) \\
\hline \multirow[t]{2}{*}{ Age in (day) } & $0-3$ & $84(71.8)$ & $100(74.6)$ & $184(73.3)$ \\
\hline & $>3-28$ & $33(28.2)$ & $34(25.4)$ & $67(26.7)$ \\
\hline \multirow[t]{2}{*}{ Sex } & Male & $68(58.1)$ & $81(60.4)$ & $149(59.4)$ \\
\hline & Female & 49 (41.9) & 53 (39.6) & $102(40.6)$ \\
\hline \multirow[t]{2}{*}{ Residence } & Urban & 70 (59.8) & $76(56.7)$ & $146(58.2)$ \\
\hline & Rural & $47(40.2)$ & $58(43.3)$ & $105(41.8)$ \\
\hline \multirow[t]{2}{*}{ Prolonged labor } & No & $103(88)$ & $114(85.1)$ & $217(86.5)$ \\
\hline & Yes & $14(12)$ & $20(14.9)$ & $34(13.5)$ \\
\hline \multirow[t]{2}{*}{ Prolonged rupture of membrane } & No & $94(80.3)$ & $104(77.6)$ & $198(78.9)$ \\
\hline & Yes & $23(19.7)$ & $30(22.4)$ & $53(21.1)$ \\
\hline \multirow[t]{2}{*}{ Fever during per partum period } & No & $102(87.2)$ & $117(87.3)$ & $219(87.3)$ \\
\hline & Yes & $15(12.8)$ & $17(12.7)$ & $32(12.7)$ \\
\hline \multirow[t]{3}{*}{ Mode of delivery } & CS & $52(44.4)$ & $29(21.6)$ & $81(32.3)$ \\
\hline & SVD & $60(51.3)$ & $100(74.6)$ & $160(63.7)$ \\
\hline & Instrumental & $5(4.3)$ & $5(3.7)$ & $10(4)$ \\
\hline \multirow[t]{2}{*}{ History of UTI during gestational period } & No & $92(78.6)$ & $104(77.6)$ & $196(78.1)$ \\
\hline & Yes & $25(21.4)$ & $30(22.4)$ & $55(21.9)$ \\
\hline \multirow[t]{2}{*}{ Getting treatment for UTI } & No & $12(10.3)$ & $15(11.2)$ & $27(10.8)$ \\
\hline & Yes & $13(11.1)$ & $15(11.2)$ & $28(11.2)$ \\
\hline \multirow[t]{3}{*}{ Gestational week } & Preterm $<37$ wks & $75(64.1)$ & $17(12.7)$ & $92(36.7)$ \\
\hline & Term 37-42 wks & $42(35.9)$ & $101(75.4)$ & $143(57)$ \\
\hline & Post term $>42$ wks & $0(0)$ & $16(11.9)$ & $16(6.4)$ \\
\hline \multirow[t]{3}{*}{ Birth Weight } & Very low $<1.5 \mathrm{~kg}$ & $40(34.2)$ & $6(4.5)$ & $46(18.3)$ \\
\hline & Low $1.5-2.5 \mathrm{~kg}$ & $37(31.6)$ & $24(17.9)$ & $61(24.3)$ \\
\hline & Normal >2.5 kg & $40(34.2)$ & $104(77.6)$ & $144(57.4)$ \\
\hline \multirow[t]{2}{*}{ Apgar score } & Low $<7 / 5$ min & $49(41.9)$ & $69(51.5)$ & $118(47)$ \\
\hline & Normal >7 /5 min & $68(58.1)$ & $65(48.5)$ & $133(53)$ \\
\hline \multirow[t]{2}{*}{ Previous history of neonatal admission } & No & $109(93.2)$ & $125(93.3)$ & $234(93.2)$ \\
\hline & Yes & $8(6.8)$ & $9(6.7)$ & $17(6.8)$ \\
\hline \multirow[t]{2}{*}{ Bottle feeding } & No & $112(95.7)$ & $127(94.8)$ & $239(95.2)$ \\
\hline & Yes & $5(4.3)$ & $7(5.2)$ & $12(4.8)$ \\
\hline \multirow[t]{2}{*}{ Skin/Local infection } & No & $108(92.3)$ & $126(94)$ & $234(93.2)$ \\
\hline & Yes & $9(7.7)$ & $8(6)$ & $17(6.8)$ \\
\hline
\end{tabular}

Key: CS Cesarean Section, SVD Spontaneous Vaginal Delivery

times more likely to develop sepsis compared to those neonates born in gestation $\geq 37$ weeks. Neonates born with very low birth weight $<1.5 \mathrm{~kg}$ had 12 times more likely to develop neonatal sepsis as compared to normal birth weight $>2.5 \mathrm{~kg}$. Neonates born with birth weight $<2500$ Gram had 3 times more likely to develop sepsis than neonates with normal birth weight. Apgar score $<7$ pre five minute had 0.5 times more likely to develop sepsis than neonates with normal Apgar score.
Caesarian section mode of delivery had 5 time risk to develop neonatal sepsis than spontaneous vaginal delivery.

\section{Discussion}

The overall culture positivity rate of bacterial isolates identified from patients with symptoms of neonatal septicemia were $46.6 \%$, comparable with the results reported from Addis Ababa (44.7\%) and Egypt 
Table 2 Distribution of bacterial isolates from neonates based on their age of admission at University of Gondar Hospital, Northwest Ethiopia, September/2015 to May/2016

\begin{tabular}{|c|c|c|c|}
\hline \multirow[t]{2}{*}{ Isolated organism } & \multicolumn{2}{|c|}{ Age at time of admission } & \multirow{2}{*}{$\begin{array}{l}\text { Total isolates } \\
N(\%)\end{array}$} \\
\hline & $\begin{array}{l}0-3 \text { day } \\
\text { n (\%) }\end{array}$ & $\begin{array}{l}>3-28 \text { day } \\
\text { n (\%) }\end{array}$ & \\
\hline S. aureus & $34(69.38)$ & $15(30.62)$ & $49(40.8)$ \\
\hline Cons & $18(69.2)$ & $8(30.8)$ & $26(21.7)$ \\
\hline S. pyogenes & $5(83.33)$ & $1(16.67)$ & $6(5)$ \\
\hline E. coli & $9(75)$ & $3(25)$ & $12(10)$ \\
\hline K. pneumoniae & $13(68.43)$ & $6(31.57)$ & 19 (15.8) \\
\hline Others & $08(100)$ & $0(0)$ & $08(6.7)$ \\
\hline Total & $87(72.5)$ & $33(27.5)$ & $120(100)$ \\
\hline
\end{tabular}

Key: Others: Serratia $(n=1)$, E. cloacae $(n=4)$ and $K$. rhinose $(n=3)$, CoNs: Coagulase Negative Staphylococcus

(40.7\%) [23, 24]. But, it is lower than study done in Sudan (61.3\%) and Yemen (57\%) [25, 26]. On the other hand, the present study is higher than from study done in Nepal (20.3\%), Tanzania (19.2\%) and Gondar (32.1\%) [27-29]. This could be due to fact methodological variation, and difference in study setting might affect culture positivity rate. Besides, in previous study in Gondar, antibioti was seen that could minimize culture positivity rate.

In our finding, the predominant isolates from Gram positive and negative bacteria were S. aureus, 49 (40.8\%) and K. pneumoniae, 19 (15.8\%), respectively. Similarly, previous studies claimed that those isolates were also the major pathogens of neonatal septicemia [24-31]. In fact $S$. aureus is ubiquitous in nature, which is frequently found on the skin, and main cause of various type of infection in human beings, therefore, newborns can easily contaminated by this bacteria from their mothers during or after delivery [32, 33]. Likewise, K. pneumoiae is a normal member of gastro-intestinal flora and recently, has emerged as a significant cause of hospital acquired infections (urinary tract infection, pneumonia and septicemia). Particularly pre-mature populations are easily colonized by the bacteria, due to the fact that, infection of neonates by this bacterium is inevitable $[34,35]$.
Moreover, the overall MDR prevalence was 78 (65\%). Among MDR Gram positive and negative bacteria, S. aureus, 30 (61.2\%) and K. pneumoniae, $14(74 \%)$ were the principal MDR strains. It is understood that $S$. auerus has remarkable feature to adapt antimicrobial pressures. Largely, it has genetic competence to acquire antibiotic resistance genes from other strains. K. pneumonia has also intrinsic resistance mechanisms, most importantly, it has chromosomal and plasmid encoded beta-lactam hydrolyzing enzymes (e.g. ESBLs) [36, 37]. Similarly, the issue of antibiotic resistance in the above mentioned bacteria have also documented in previous reports [28, 31, 38-40].

Specific antibiotic resistance has also indicated in the present study. Hence, ampicillin was the most ineffective antibiotics for both Gram positive and negative bacteria. It is well understood; the consequence of ampicillin resistance is mainly due to selective pressure excreted by overuse of the antibiotics. Apart from that, it is also known that bacteria showed resistance genes for beta-lactam agents including ampicllin. Similarly, consistent finding were also claimed in Addis Ababa, Gondar and Egypt with high degree of resistance to ampicillin in both Gram positive and negative bacteria [23, 28, 38, 39].

In our study, the incidence of sepsis was higher in neonates, who were born by caesarian section, thus the odds of developing sepsis among neonates born with caesarian section was five times more likely to develop sepsis to their counterparts. This finding is similar to other previous studies from Iran and Egypt [23, 38]. Reasonably, bleeding is common during surgical procedures, thus, it could be the possible factor that results to blood contamination, subsequently leads bacterial sepsis in neonates. Particularly, Neonates are vulnerable to nosocomial infections because of their reduced immunological profiles as well as the invasive procedures to which they are subjected. This is highly appreciated for those born prematurely or of low birth weight [41]. Likewise, different studies came up with the conclusion that low birth weight infants

Table 3 Antimicrobial susceptibility patterns of Gram positive bacteria from blood cultures in neonatal sepsis, University of Gondar Hospital, Northwest Ethiopia, September/2015 to May/2016

\begin{tabular}{|c|c|c|c|c|c|c|c|c|c|c|c|c|}
\hline \multirow[t]{2}{*}{ Bacterial isolates } & \multicolumn{12}{|c|}{ Resistance rate N (\%) } \\
\hline & $P$ & AMP & OXA & CXT & SXT & $\mathrm{CIP}$ & $\mathrm{CRO}$ & TE & CAF & E & $\mathrm{CN}$ & DA \\
\hline S. aureus $(n=49)$ & $25(51)$ & $20(41)$ & $13(27)$ & $13(27)$ & $18(37)$ & $10(20)$ & $12(24.5)$ & $16(33)$ & $15(30.6)$ & $18(37)$ & $19(38.8)$ & $04(8.1)$ \\
\hline CoNs $(n=26)$ & $17(65)$ & $10(38)$ & $10(38)$ & $10(38)$ & $12(46)$ & $05(19)$ & $08(30.8)$ & $11(42)$ & $10(38)$ & $11(42)$ & $14(53.8)$ & $02(7.7)$ \\
\hline S.pyogenes $(n=6)$ & $0(0)$ & $0(0)$ & $1(17)$ & $1(17)$ & $4(67)$ & $1(17)$ & $2(33.3)$ & $1(17)$ & $1(17)$ & $1(17)$ & $2(33.3)$ & $1(17)$ \\
\hline Total = 81 & $42(52)$ & $30(37)$ & $24(30)$ & $24(30)$ & $34(42)$ & $16(20)$ & $22(27.2)$ & $28(34)$ & $22(27)$ & $30(37)$ & $28(35)$ & $07(8.6)$ \\
\hline
\end{tabular}


Table 4 Antimicrobial susceptibility patterns of Gram negative bacteria from blood cultures in neonatal sepsis, University of Gondar Hospital, Northwest Ethiopia, September/2015 to May/2016

\begin{tabular}{|c|c|c|c|c|c|c|c|c|c|c|}
\hline \multirow{2}{*}{ Bacterial isolates } & \multicolumn{10}{|c|}{ Number of resistance to antimicrobial agents (\%) } \\
\hline & SXT & AMC & TE & CIP & $\mathrm{CN}$ & $\mathrm{CRO}$ & AK & AMP & CAZ & CAF \\
\hline E.coli $(n=12)$ & $04(33.3)$ & $3(25)$ & $2(16.7)$ & $0(0)$ & $1(8.3)$ & $3(25)$ & $0(0)$ & $8(66.7)$ & $1(8.3)$ & $2(16.7)$ \\
\hline K.pneumoniae $(n=19)$ & $8(42.1)$ & $6(31.6)$ & $7(36.8)$ & $3(15.8)$ & $3(15.8)$ & $15(78.9)$ & $2(10.52)$ & $18(94.7)$ & $2(10.5)$ & $6(31.6)$ \\
\hline Others $(n=08)$ & $05(62.5)$ & $02(25)$ & $01(12.5)$ & $02(25)$ & $01(12.5)$ & $04(50)$ & $0(0)$ & $07(87.5)$ & $02(25)$ & $02(25)$ \\
\hline Total = 39 & $17(43.58)$ & $11(28.2)$ & $10(25.6)$ & $5(12.8)$ & $5(12.8)$ & $22(56.4)$ & $2(5.1)$ & 33 (84.6\%) & $5(12.8)$ & $10(25.6)$ \\
\hline
\end{tabular}

Key: SXT Trimethoprim- sulfamethoxazole, AMC Amoxicillin-clavulanate, TE Tetracycline, Amp Ampicillin, CIP Ciprofloxacin, CN Gentamicin, AK Amikacin, CRO Ceftriaxon, CAZ: Ceftazidamide, CAF Chloramphenicol, Others:Seratiaspecies (01), Enterobactor species (04) and K. rhinose (03)

are at high risk of developing sepsis compared to normal birth weight [42].

It is largely understood that prolonged rupture of membrane and prolonged labor are the commonly associated risk factors for the occurrence of neonatal sepsis because of the danger of ascending infection. However, the present study indicated that no significant associations with the above mentioned variables. This study showed that low Apgar score at 5th minute had a significant effect on the development of neonatal sepsis; this result is consistence with study conducted in Mekelle, Indonesia and Nepal [43-45]. In general Apgar score at the first minute associated with the Hydrogen Potential $(\mathrm{pH})$ cord blood and intra partum depression and not associates with the outcomes, whereas the Apgar score/5 min then reflects the infants' changes condition on the resuscitation performed [44].

In the present study, gestational week $<37$ was also the risk factor with nine times higher risk to develop sepsis than gestational week $>37$. Similarly, studies conducted in Addis Ababa, Nepal, Mexico and Indonesia, have also documented that gestation $<37$ weeks had significant association with neonatal sepsis [39, 43, 44, 46]. Evidently, preterm baby may have a limited capacity to increase neutrophil production in accordance to demand to overcome the problem. Neutropenia and depleted neutrophil storage pools have been found to be associated with neonatal bacterial sepsis and are predictive of a poor prognosis [47].

In this study very low birth weight and low birth weight had significant association with the occurrence of sepsis; this is consistent with studies conducted in Nepal and Indonesia [43, 44]. Immunological barriers began to mature around 32-34 weeks of gestation and accelerated after birth. That's why the level mucosal antibody is low in underweight neonates [48]. the deficiency of molecular reactants phase such as $C$ - reactive proteins, inhibitor protein and several of the coagulation proteins have been also demonstrated in immature neonates. Moreover, pre-term baby had a lot of neutrophil in circulatory pool but it reserves in the bone marrow is only about $20 \%$ compared to the term baby and adults so that the state of sepsis occur severe neutropenia [48-50].

\section{Limitation of the study}

A specific characterization MDR bacterium (MRSA, ESBL) has not been done due to lack of well-established methodological techniques. Moreover, molecular based specification for some bacterial groups (CoNS) was not done.

Table 5 Multi drug resistance pattern of bacterial isolates in neonatal septicemia, University of Gondar Hospital North West Ethiopia, from September/2015 to May/2016

\begin{tabular}{|c|c|c|c|c|c|c|c|c|c|}
\hline \multirow[t]{2}{*}{ Organism isolated } & \multicolumn{8}{|c|}{ Degree of resistance } & \multirow{2}{*}{$\begin{array}{l}\text { Total MDR } \\
\text { isolates } \geq R 3\end{array}$} \\
\hline & Ro (\%) & R1 (\%) & R2 (\%) & R3 (\%) & R4 (\%) & R5 (\%) & R6 (\%) & R7 (\%) & \\
\hline S. aureus $(n=49)$ & $08(16.3)$ & $02(4)$ & 09 (18.3) & 09 (18.3) & $06(12.2)$ & $06(12.2)$ & $06(12.2)$ & $03(6.1)$ & $30(61.2)$ \\
\hline CoNS $(n=26)$ & $02(7.7)$ & $02(7.7)$ & $01(3.8)$ & $00(0)$ & $07(26.9)$ & 09 (34.6) & $03(11.5)$ & $02(7.7)$ & $21(81.0)$ \\
\hline S. pyogenes $(n=6)$ & - & - & $01(16.7)$ & $03(50)$ & $02(33.3)$ & - & - & - & 05 (83.3) \\
\hline E. coli $(n=12)$ & - & $04(33.3)$ & $05(41.7)$ & $02(16.7)$ & - & - & $01(8.3)$ & - & $03(25.0)$ \\
\hline K.pnuemoniae $(n=19)$ & $01(5.2)$ & $02(10.5)$ & $02(10.5)$ & $05(26.3)$ & $04(21)$ & $01(5.2)$ & $02(10.5)$ & $02(10.5)$ & $14(74.0)$ \\
\hline Others $(n=8)$ & - & $01(12.5)$ & $02(25)$ & $02(25)$ & - & $01(12.5)$ & $02[25]$ & - & $05(62.5)$ \\
\hline Total $n=120$ & $11(9.2)$ & $11(9.2)$ & $20(16.7)$ & $21(17.5)$ & 19 (15.8) & $17(14.2)$ & $14(11.6)$ & $07(5.8)$ & $78(65.0)$ \\
\hline
\end{tabular}

Key:CoNS Coagulase Negative Staphylococcus, others: Seratiaspecies, E. cloaca, K. rehinose, R0: susceptible to all antibiotics, R1-7: resistance to 1,2, 3, 4, 5, 6 \& 7 antibiotics, $\geq$ R3: resistance to 3 or more antibiotic 
Table 6 Univariate and multivariate analysis on risk factors associated with positivity rate of neonatal Septicemia at University of Gondar Hospital, Northwest Ethiopia September/2015 to May/2016

\begin{tabular}{|c|c|c|c|c|c|c|}
\hline \multirow[t]{2}{*}{ Variable } & \multicolumn{2}{|c|}{ Bacterial isolates } & \multicolumn{2}{|l|}{ Univariate analysis } & \multicolumn{2}{|l|}{ Multi variate analysis } \\
\hline & Yes $=117$ & $\mathrm{No}=134$ & COR(95\% Cl) & $P$-value & $\mathrm{AOR}(95 \% \mathrm{Cl})$ & $P$-value \\
\hline \multicolumn{7}{|c|}{ Mode of delivery } \\
\hline CS & 52 & 29 & $2.989(1.714,5.21)$ & $<0.001$ & $5.191(2.36,11.37)$ & $<0.001$ \\
\hline I & 5 & 5 & $1.667(0.463,599)$ & 0.434 & $5.26(0.875,31.7)$ & 0.070 \\
\hline SVD & 60 & 100 & 1 & & 1 & \\
\hline \multicolumn{7}{|c|}{ Gestational week } \\
\hline Pre term & 75 & 17 & $10.7(5.607,20.074)$ & $<0.001$ & $8.99(4.175,19.38)$ & $<0.001$ \\
\hline Term & 42 & 101 & 1 & & 1 & \\
\hline \multicolumn{7}{|l|}{ Birth weight } \\
\hline Very low & 40 & 6 & $17.3(6.823,44.03)$ & $<0.001$ & $12.37(4.135,37.04)$ & $<0.001$ \\
\hline Low & 37 & 24 & $4.0(2.135,7.526)$ & $<0.001$ & $2.63(1.149,6.09)$ & 0.022 \\
\hline Normal & 40 & 104 & 1 & & 1 & \\
\hline \multicolumn{7}{|l|}{ Apgar score } \\
\hline Low & 49 & 69 & $0.679(0.412,1.12)$ & 0.129 & $0.438(0.215,0.892)$ & 0.023 \\
\hline Normal & 68 & 65 & 1 & & 1 & \\
\hline
\end{tabular}

\section{Conclusion}

High prevalence of bacterial isolates was observed in this study. S. aureus was the predominant pathogen from Gram positive and $K$. pneumonia was from Gram negative. The overall prevalence of MDR was high. Comparably high level of resistance to ampicillin was observed among Gram positive and Gram negative bacteria.The most common risk factors for neonatal sepsis infection observed in this study were caesarian section mode of delivery, Apgar score $<7$, birth weight $<2.5 \mathrm{~kg}$ and gestational week $<37$ weeks. Substantially, strengthening of antenatal screening of mothers, prenatal care of newborns and interventions of babies born with complications are the key elements to control the problem. Moreover, Empirical regimens for neonatal sepsis using ampicillin and gentamicin must be taken into consideration due to the risk of resistance, misdiagnosis and mismanagement.

\section{Additional file}

Additional file 1: Questionnaire. (DOCX $14 \mathrm{~kb})$

\section{Abbreviations}

CoNS: Coagulase negative Staphylococcus species; CSF: Cerebrospinal fluid; ESBL: Extended spectrum beta lactamase; MDR: Multi Drug resistant; MRSA: Methicilin resistant staphylococcus aureus; UTI: Urinary tract infection

\section{Ethical approval and consent to participate}

Ethical clearance was obtained from the research and ethics committee of the School of Biomedical and Laboratory Sciences, University of Gondar prior the initiation of the study. There is no additional sample to be taken from the study participants for the sake of this study. The blood sample collected in the study was part of the routine patient investigation and management at the neonatology ward. A written informed consent was obtained from mothers/caretakers of neonates after explaining the purpose and objective of the study. The blood sample was collected by experienced pediatric nurses as part of the routine sample collection at neonatology ward. The result was communicated to the treating physician for immediate and appropriate treatment. Confidentiality was kept through using codes instead of names in all the study process.

\section{Funding}

The study was supported by the mega project of the University of Gondar in Reference number of VP/RCS/05/192/2015 and by Armauer Hansen Research Institute.

\section{Availability of data and materials}

Additional file 1 Questionnaire.

\section{Authors' contributions}

TG and FM conception of research idea, study design, data collection, analysis and interpretation. SE conception of research idea, study design data collection, analysis, interpretation and the drafting of manuscript. FY and EA data collection, analysis and interpretation and supervision. All authors read and approved the final manuscript.

\section{Competing interests}

The authors declare that they have no competing interests.

Consent for publication

Not applicable.

\section{Publisher's Note}

Springer Nature remains neutral with regard to jurisdictional claims in published maps and institutional affiliations. 


\section{Author details}

Amhara Regional Health Bureau, South Gondar Zonal Health Bureau, Debre Tabor, , Ethiopia. ${ }^{2}$ Department of Medical Microbiology, School of Biomedical and Laboratory Sciences, College of Medicine and Health Sciences, University of Gondar, Gondar, P. O. Box: 196, Ethiopia. ${ }^{3}$ Armauer Hansen Research Institute (AHRI), Addis Ababa, , Ethiopia.

\section{Received: 10 January 2017 Accepted: 29 May 2017}

\section{Published online: 06 June 2017}

\section{References}

1. Sankar MJ, Agarwal R, Deorari AK, Paul VK. Sepsis in the newborn. Indian J Pediatr. 2008;75(3):261-6.

2. Lever A, Mackenzie I. Sepsis: definition, epidemiology, and diagnosis. Br med J. 2007;3(7):879.

3. Shaha C, Dey S, Shabuj H, Chisti J, Mannan M, Jashimuddin M, et al. Neonatal sepsis review. Bangladesh J Child Health. 2012;36(2):82-9.

4. Puopolo K. Epidemiology of neonatal early-onset sepsis. Neo Reviews. 2008; 9(12):571-9.

5. Zakariya B, Bhat V, Harish N, Babu T, Joseph M. Neonatal sepsis in a tertiary care hospital in South India: bacteriological profile and antibiotic sensitivity pattern. Indian J Pediatr. 2011;78(4):413-7.

6. Tallur S, Kasturi A, Nadgir S, Krishna B. Clinico-bacteriological study of neonatal septicemia in Hubli. Indian J Pediatr. 2000;67(3):169-74.

7. Karunasekera K, Pathirana D. A preliminary study on neonatal septicaemia in a tertiary referral hospital paediatric unit. Ceylon Med J. 1999:44(2):81-6.

8. Shah BA, Padbury JF. Neonatal sepsis: An old problem with new insights. Virulence. 2014;5(1):170-78. doi:10.4161/viru.26906.

9. Simonsen KA, Anderson-Berry AL, Delair SF, Davies HD. Early-onset neonatal sepsis. Clin Microbiol rev. 2014;27(1):21-47.

10. Stoll BJ, Hansen N, Fanaroff AA, Wright LL, Carlo WA, Ehrenkranz RA, et al. Late-onset sepsis in very low birth weight neonates: the experience of the NICHD neonatal research network. Pediatrics. 2002;110(2):285-91.

11. Mohammad S, Aletayeb H, Khosravi AD, Dehdashtian M, Kompani F, Mortazavi M, et al. Identification of bacterial agents and antimicrobial susceptibility of neonatal sepsis: a 54-month study in a tertiary hospital. Afr J Microbiol res. 2011;5:528-31.

12. Shaw G, Sim K, Randell P, Cox J, McClure Z, Li M-S, et al. Late-Onset Bloodstream Infection and Perturbed Maturation of the Gastrointestinal Microbiota in Premature Infants. PloS one. 2015;10(7):e0132923.

13. Afsharpaiman S, Torkaman M, Saburi A, Farzaampur A, Amirsalari S, Kavehmanesh Z. Trends in incidence of neonatal sepsis and antibiotic susceptibility of causative agents in two neonatal intensive care units in tehran, Iran. J Clin Neonatol. 2012;1(3):124-30.

14. Knippenberg R, Lawn J, Darmstadt L, Begkoyian G, Fogstad H, Walelign N, et al. Systematic scaling up of neonatal care in countries. Lancet. 2005;36(9): 1087-98.

15. Shah GS, Budhathoki S, Das BK, Mandal RN. Risk factors in early neonatal sepsis. Kathmandu Univ med J. 2006;4(2):187-91

16. World Health Organization. Countdown to 2015, maternal, newborn \& child survival-fulfilling the health agenda for women and children: the 2014 report. Geneva: WHO press; 2014

17. Costello A, Francis V, Byrne A, Puddephatt C. State of the World's Newborns: A Report from Saving Newborn Lives: 2001. Available at http://files.eric.ed. gov/fulltext/ED458972.pdf.

18. Jyothi P, Basavaraj C, Basavaraj P. Bacteriological profile of neonatal septicemia and antibiotic susceptibility pattern of the isolates. J Nat sc Biol med. 2013;4(2):306.

19. Paolucci M, Landini P, Sambri V. How can the microbiologist help in diagnosing neonatal sepsis? Int J Pediatr. 2012;120139(10):26.

20. Cheesbrough M. District laboratory practice in tropical countries: Cambridge university press; 2006. Available at http://fac.ksu.edu.sa/sites/default/files/ Book-District_Laboratory_Practice_in_Tropical_Countries_Part-2_Monica_ Cheesbrough.pdf

21. Clinical and laboratory standard inustitut. Performance standards for antimicrobial susceptibility testing:twenty-forth informational supplement CLSI document M100-S24CLS. 2014;34(1).

22. Clinical and Laboratory Standards Institute (CLSI). Methods for dilution antimicrobial susceptibility tests for bacteria that grow aerobically: approved standard-Tenth Edition. CLSI document M07-A10. Wayne: CLSI; 2015.
23. Shehab E, El-Sokkary A, Bassiouny R, Hassan R. Epidemiology of neonatal sepsis and implicated pathogens: a study from Egypt. Biomed res Int. 2015; 509484(10):4.

24. Shitaye D, Asrat D, Woldeamanuel Y, Worku B. Risk factors and etiology of neonatal sepsis in Tikur Anbessa university hospital, Ethiopia. Ethiop Med J. 2010:48(1):11-21.

25. Al-Shamahy H, Sabrah A, Al-Robasi B, Naser M. Types of bacteria associated with neonatal sepsis in al-Thawra university hospital, Sana'a, Yemen, and their antimicrobial profile. Sultan Qaboos Univ med J. 2012;12(1):48.

26. Kheir A, Khair R. Neonatal sepsis; prevalence and outcome in a tertiary neonatal unit in Sudan. Time J Med Sci. 2014;2:21-5.

27. Khanal R, Manandhar S, Acharya G. Bacteriological profile of neonatal sepsis in a tertiary level Hospital of Nepal. J Nepal Paediatr soc. 2015;34(3):175-80.

28. Gebrehiwot A, Lakew W, Moges F, Anagaw B, Yismaw G, Unakal C. Bacterial profile and drug susceptibility pattern of neonatal sepsis in Gondar University hospital, Gondar Northwest Ethiopia. Der Pharmacia Lettre. 2012; 4(6):1811-6.

29. Mkony F, Mizinduko M, Massawe A, Matee M. Management of neonatal sepsis at Muhimbili National Hospital in Dar es salaam: diagnostic accuracy of C-reactive protein and newborn scale of sepsis and antimicrobial resistance pattern of etiological bacteria. BMC Pediatr. 2014;14(1):1.

30. Khan M, Khan A, Shah F, Munir A. Neonatal sepsis: a study of causative pathogens and their antimicrobial sensitivity pattern at tertiary hospital. Gomal J Med Sci. 2012;10(2):244-7.

31. Onyedibe Kl, Bode-Thomas F, Nwadike V, Afolaranmi T, Okolo M, Uket O. High rates of bacteria isolates of neonatal sepsis with multidrug resistance patterns in Jos Nigeria. Ann Tropl Pediatr Int Child Health. 2015;3:1052.

32. Naber C. Staphylococcus aureus Bacteremia: epidemiology, pathophysiology, and management strategies. Clin Infect Dis. 2009:48(4):231-7.

33. Jimenez N, Tedeschi S, Saye EJ, McKenna BD, Langdon W, Wright JP, et al. Relationship between maternal and neonatal Staphylococcus aureus colonization. Pediatrics. 2012;129(5):1252-9.

34. Zaidi K, Thaver D, Ali S, Khan T. Pathogens associated with sepsis in newborns and young infants in developing countries. Pediatr Infect Dis J. 2009;28(1):10-8

35. Ghotaslou R, Ghorashi Z, Nahaei M. Klebsiella pneumoniae In neonatal sepsis: a 3-year-study in the pediatric hospital of Tabriz Iran. Jpn J Infect Dis. 2007; 60(2/3):126

36. Thenmozhi S, Moorthy M, Sureshkumar B, Suresh M. Antibiotic resistance mechanism of ESBL producing Enterobacteriaceae in clinical field: a review. In J Pure Appl Biosci. 2014;2:207-26.

37. Östholm Balkhed Å. Extended-Spectrum ß-Lactamase-Producing Enterobacteriaceae: Antibiotic consumption, Detection and Resistance Epidemiology. Linköping: Linköping University Electronic Press; 2014.

38. Aamir M, Ali E, Hamouda M, Mourad F. Prevalence of multi drug resistant bacteria causing late-onset neonatal sepsis. Int J Curr Microbiol app Sci. 2015;4(5):172-90.

39. Yusuf A, Worku B. Descriptive cross-sectional study on neonatal sepsis in the neonatal intensive care unit of Tekur Anbessa hospital, Addis Ababa, Ethiopia. Ethiop J Pediatr Child Health. 2010;6(6):50-4.

40. Kayange N, Kamugisha E, Mwizamholya DL, Jeremiah S, Mshana SE. Predictors of positive blood culture and deaths among neonates with suspected neonatal sepsis in a tertiary hospital, Mwanza-Tanzania. BMC pediatrics. 2010;10(1):1.

41. Vergnano S, Sharland M, Kazembe P, Mwansambo C, Heath P. Neonatal sepsis: an international perspective. Arch Dis Child Fetal Neonatal Ed. 2005; 90(3):220-4.

42. Dhumal P, Ujagare M, Gandham N, Nagdawane R, Sardar M, Sharma M, et al. Incidence and antimicrobial susceptibility pattern of neonatal septicaemia from tertiary care hospital of India. Int J Med Clin Res. 2012;3(7):207.

43. Shah G, Budhathoki S, Das B, Mandal R. Risk factors in early neonatal sepsis. Kathmandu Univer Med J (KUMJ). 2005:4(2):187-91.

44. Muhammad Hayun, Ema Alasiry, Dasril Daud, Dwi Bahagia Febriani, Djauhariah Madjid, The Risk Factors of Early Onset Neonatal Sepsis, American Journal of Clinical and Experimental Medicine. 2015;3(3): 78-82. doi:10.11648/j.ajcem.20150303.11.

45. Gebremedhin D, Berhe H, Gebrekirstos K. Risk Factors for Neonatal Sepsis in Public Hospitals of Mekelle City, North Ethiopia, Unmatched Case Control Study. PloS one. 2016;11(5):e0154798. 
46. Leal Y, Álvarez VJ, Rosado U, Diego N, Paz E, et al. Risk factors and prognosis for neonatal sepsis in southeastern Mexico: analysis of a four-year historic cohort follow-up. BMC Pregnancy Childbirth. 2012;12(1):1.

47. Petrova A, Mehta R. Dysfunction of innate immunity and associated pathology in neonates. Indian J Pediatr. 2007;74(2):185-91.

48. Benitz W, Gould B, Druzin L. Risk factors for early-onset group B Streptococcal sepsis: estimation of odds ratios by critical literature review. Pediatrics. 1999; 103(6):77.

49. Gerdes JS. Diagnosis and management of bacterial infections in the neonate. Pediatr Clin N am. 2004;51(4):939-59.

50. Mussi M, Rego A. Immunological peculiarities of extremely preterm infants: a challenge for the prevention of nosocomial sepsis. J Pediatr. 2005;81(1): 59-68.

Submit your next manuscript to BioMed Central and we will help you at every step:

- We accept pre-submission inquiries

- Our selector tool helps you to find the most relevant journal

- We provide round the clock customer support

- Convenient online submission

- Thorough peer review

- Inclusion in PubMed and all major indexing services

- Maximum visibility for your research

Submit your manuscript at www.biomedcentral.com/submit
Biomed Central 